
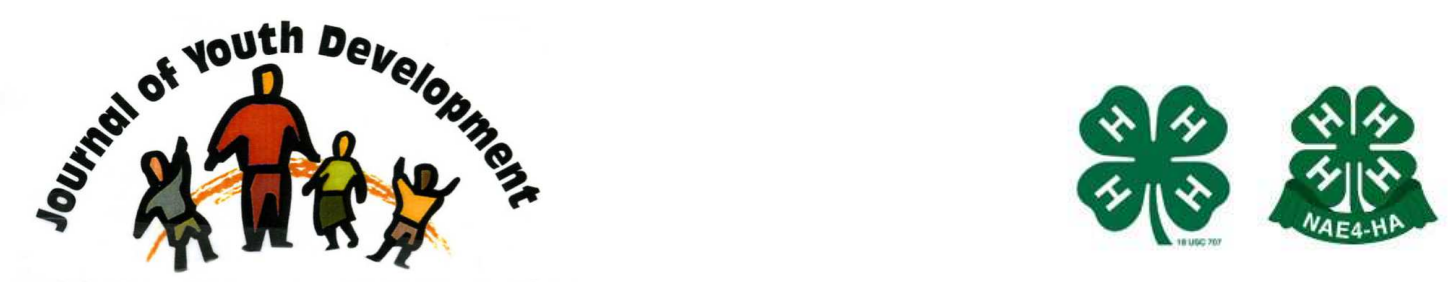

Bridging Research \& Practice

\title{
Learn to Live: \\ Simple and Practical Activities to Promote Health, Nutrition and Physical Fitness in the K-8 Curriculum
}

\author{
Ali Ann Y. Dirga \\ Willamette University \\ Salem, Oregon \\ adiga@willamette.edu
}

Stasinos Stavrianeas

Willamette University

Salem, Oregon

stas@willamette.edu 


\title{
JOURNAL OF YOUTH DEVELOPMENT \\ bridging research and practice

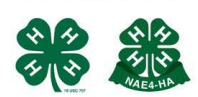

Volume 3, Number 2, Fall 2008

Article 080302RR001

\section{Learn to Live: \\ Simple and Practical Activities to Promote Health, Nutrition and Physical fitness in the K-8 Curriculum}

\author{
Ali Ann Y. Dirga, Stasinos Stavrianeas \\ Willamette University
}

\begin{abstract}
Current health education and physical fitness programs have failed to prevent the youth obesity epidemic. The diminishing emphasis placed on such programs due to curricular and budgetary constraints results in few opportunities to promote students' active participation in regular physical activity and health education programs. Findings indicate that a successful program to promote healthy nutrition, an active lifestyle, and regular physical exercise requires that the information is easily accessible, and presented in a clear and concise format. Readers are introduced to a comprehensive program, easily adjustable throughout the K-8 curriculum. It is designed to complement regular classroom activities by introducing a series of stand-alone lessons and activities to educate students on the benefits of regular exercise and healthy lifestyle. This program can be used in any community and can offer the youth population the information they need to create healthy habits that will last a lifetime.
\end{abstract}

\section{Introduction}

In the United States, over $18 \%$ of children ages 6-11 are obese; a number which is rising rapidly each year (American Obesity Association, 2002). If these children continue to be overweight throughout their childhood and adolescence, they will have a $70 \%$ chance of being overweight or obese as adults (U.S. Department of Health \& Human Services, 2006). It is well known that overweight children are at risk of developing health problems such as diabetes as well as self-esteem issues (Gidding et al., 1996). Several studies have pointed out that as obese children mature into overweight adults, they will be at risk for cardiovascular disease, high blood pressure, stroke, and diabetes (U.S. Department of Health \& Human Services, 2006). The growing rate of childhood obesity has illustrated that dealing with obesity needs to start with our youth. 
Many schools have reduced class time for physical education programs due to budgetary constraints and school policies (American Heart Association, 2006). As explained later, these schools will benefit from a supplementary health program because they are not meeting the government requirements for physical education and health. A study done by Cornell University found that even if schools offer physical education classes, their students may not be exercising sufficiently. Students are not motivated to participate in physical education programs nor do they understand the importance of them since they are not educated about these issues (Crawley, 2006). It is imperative to the success of a health program that students be taught the reasons that physical activity and a nutritious diet are important parts of life. There is a need for an education program that promotes a healthy lifestyle and regular physical exercise to youth in schools.

The National Institute of Health has compiled a list of key strategies to fight the youth obesity epidemic. These strategies include:

- addressing physical activity and nutrition through a coordinated school curriculum,

- implementing a high-quality health promotion program, and

- including courses in health and physical education.

A program that addresses these key strategies through a series of stand-alone lessons to compliment regular classroom activities had been proposed. These activities will focus on creating healthy habits, emphasizing nutrition, physical fitness, and simple physiology. Easily implemented by any educator, these lessons will teach the fundamentals of a healthy lifestyle, thereby offering and important strategy in the fight against childhood obesity.

\section{Resource Design}

Implementation of a successful health education program requires information to be easily accessible and presented in a clear and concise format. In the absence of any available comprehensive and low-cost program, the Learn to Live curriculum was developed last year. Learn to Live is a complete program, easily adjustable throughout grades $\mathrm{K}-8$, and it includes a series of stand-alone lessons designed to complement regular classroom activities. Lessons are developed to include the Hawaii Department of Education Standards concerning health, nutrition and physical education, and include "hands-on" activities to encourage students to be interested and involved.

Our review of the available literature indicates that programs that combine education with hands-on activities yield best results in terms of student comprehension and retention. Accordingly, Learn to Live is unique because it combines nutrition, physical, fitness, tobacco education, germ awareness, simple physiology, and numerous other relevant topics into one complete package. Furthermore, the "Learn to Live" program is cost effective because any teacher can use it in his or her classroom, eliminating the need to hire additional educators to implement the lessons.

The goal of the Learn to Live program is to fight the obesity epidemic by educating students about the importance of a healthy lifestyle from a young age. This is accomplished through three main strategies:

1) Providing youth with the information needed to create healthy habits that will last a lifetime. 
2) Helping schools meet the Department of Education Standards for health, nutrition and physical education.

3) Instilling an interest in physical fitness and movement activities back into our youth.

\section{Learn to Live Program}

The program is designed to be simple and it can be easily used by any educator. The format includes materials that can be adjusted if need be, to fit the school or classroom in which it is being used. A binder, complete with all lesson plans, activity descriptions, handouts and evaluations, to be stationed in a central location for those who might utilize the materials. A library, or an organization which promotes community wellness, are possible locations for the materials to be reserved.

Each lesson is structured in the following order:

- title and topic area,

- Department of Education Standards covered,

- length of time needed,

- materials required,

- an overview of the lesson,

- a brief purpose statement and

- the lesson itself.

Information is presented clearly and is in a complete format, enabling teachers who have no expertise in the area to teach the lesson. Each topic includes hands-on activities suitable to a specific age level and thorough instructions for completion of the activity. Age-appropriate evaluations for the students following the lecture and activities allow feedback that could be useful if adjustments to the lesson are needed.

An example of a lesson used in the three age groups is Fun with Food. The lesson plan is altered to accommodate each age group, although the material covered is similar for each. Specific Department of Education Standards within the categories of fine arts, science, math, health, and physical education are addressed in the lesson. The K-2 Fun with Food plan begins with a discussion of the different food groups while the students color the sections of the new food guide pyramid. The activity involves creating a "healthy meal" place mat where students will draw food items from the varying food groups that they studied, to create a balanced meal. The placemat, which can be laminated using clear packaging tape, can then be used by the student either for lunch at school or taken home for his or her place at the family's dining room table. The lesson comes to an end with a "Five Food Groups" song, with the lyrics provided, sung to the tune of Twinkle, Twinkle Little Star to help the students remember what they have learned. The students also are asked to complete an evaluation, which will provide the educator with useful feedback.

The same lesson for grades 3-5 includes a discussion about the food pyramid in more depth than the K-2 lesson by exploring the importance of serving sizes and healthy food choices. The activity requires students to make their own food pyramid with healthy foods so that they realize what should be eaten in abundance and foods that should be enjoyed in moderation. Evaluations are straightforward and include questions such as "How many food groups are there and can you name them all?" to assess students comprehension of the lesson.

The 6-8 ${ }^{\text {th }}$ grade lesson goes into the most depth and begins to approach the concept of calories. The lesson begins with a discussion about what a calorie is, how many we should be 
eating, and how many of each type of food we should be consuming. The activity included in this lesson is to burn a cashew in a homemade calorimeter, which will measure the amount of heat produced and can determine how many calories the nut contains. This fairly simple yet exciting scientific experiment allows students to have hands-on experience to determine the amount of calories in a certain type of food. The evaluations for the $6-8^{\text {th }}$ graders involve more opened ended questions such as, "Discuss something that you learned today that you did not know before." Each of the lesson plans is unique but follows a format similar to the others.

The format of the program allows teachers to supplement their daily classroom activities with important instruction about health, nutrition and physical fitness without much added time and effort. While there is an abundant amount of information available regarding these subject areas, typically, an instructor must schedule many hours of research and lesson planning to create one lesson. The Learn to Live program lesson plans are available online through Tutu's House, a non-profit organization aimed at community wellness. The website can be found at www.tutushouse.org

\section{Target Audience}

The Learn to Live program targets educators of kindergarten through eighth grade students. The lesson plans are divided into three groups; kindergarten through second grade, third through fifth grade and sixth through eighth grade. The groups are consistent with the Hawaii Department of Education Standards for Health, Nutrition and Physical Education but can be adapted to meet other state standards. The standards for each group are different so creating lesson plans to target specific age groups keeps the material age-appropriate as well as satisfying government requirements.

\section{Impact of the Curriculum Resource}

A first trial of this program proved very successful when implemented at a school in Hawaii. The students actively participated in discussions and surveys showed that the students comprehended the material. Conducting a similar program within schools will promote students' active participation in regular physical fitness and health education programs. Standalone lessons will allow teachers to fit health, nutrition and physical fitness activities into normal classroom schedules with little difficulty. Providing youth with information needed to create healthy habits will have a significant impact on the way they approach physical education classes and their health in general. In this report we introduce the Live to Learn curriculum for free adoption by educators across the country. The teachers who choose to adopt the curriculum will be asked to return a survey designed to evaluate the ease of implementation, quality and depth of information, adaptability to different classes, etc. The results will be shared in a subsequent report.

\section{Summary}

The Learn to Live program has the potential to benefit youth around the country. It is accessible to teachers and will help schools to meet the government requirements for Health and Physical Fitness. A recent study done by the American Obesity Association (2002) found that $30 \%$ of parents are either somewhat or very concerned about their child's weight, physical activity, and health. As the childhood obesity epidemic continues to grow, it is essential to the well being of our youth population to implement a program that will teach them the importance 
of good health starting at a young age. Children who learn about nutrition and physical education through exciting hands-on activities and discussion will gain knowledge that will foster healthy habits for a lifetime.

\section{References}

American Heart Association. (2006). Physical Education in Schools. Online:

http://www.americanheart.org/presenter.jhtml?identifier $=3010854$

American Obesity Association. (2002). Childhood Obesity: Prevalence and Identification. Online: http://www.nydic.org/nydic

Crawley, J., Meyerhoefer, C., \& Newhouse. (2006). Not Your Father's PE. Education Next (4).

Gidding, S., Leibel, R., Daniels, S., Rosenbaum, M., Van Horn, L., \& Marx, G. (1996).

Understanding Obesity in Youth. A statement for healthcare professionals from the Committee on Atherosclerosis and Hypertension in the Young of the Council on Cardiovascular Disease in the Young and the Nutrition Committee, American Heart Association. Writing Group. American Heart Association Circulation (94, 3383-7).

U.S. Department of Health \& Human Services: U.S. Surgeon General. (2006). Overweight and Obesity: Health Consequences. Online:

http://www.surgeongeneral.gov/topics/obesity/calltoaction/fact consequences.htm

(C) Copyright of Journal of Youth Development Bridging Research and Practice. Content may not be copied or emailed to multiple sites or posted to a listserv without copyright holder's express written permission. Contact Editor at: patricia.dawson@oregonstate.edu for details. However, users may print, download or email articles for individual use.

ISSN 2325-4009 (Print); ISSN 2325-4017 (Online) 